in vivo $34: 1901-1908(2020)$

doi:10.21873/invivo.11986

\title{
Preoperative C-Reactive Protein/Albumin Ratio as a Predictive Factor for Gallbladder Carcinoma
}

\author{
MASASHI UTSUMI, HIDEKI AOKI, SEICHI NAGAHISA, SEITARO NISHIMURA, YUTA UNE, YUJI KIMURA, \\ MEGUMI WATANABE, FUMITAKA TANIGUCHI, TAKASHI ARATA, KOH KATSUDA and KOHJI TANAKAYA
}

Department of Surgery, National Hospital Organization, Iwakuni Clinical Center, Yamaguchi, Japan

\begin{abstract}
Background/Aim: The C-reactive protein (CRP) to albumin ratio (CAR) is associated with outcomes in patients with sepsis. We aimed to evaluate the significance of preoperative CAR in therapeutic outcomes after gallbladder carcinoma $(G B C)$ resection. Patients and Methods: Fifty-three patients who underwent surgical resection for GBC between January 2008 and September 2019 were enrolled. We retrospectively investigated the relation between preoperative CAR and overall and disease-free survival. Results: The optimal cut-off CAR was 0.07. Multivariate analysis showed that i) R1 or $R 2$ resection ( $p=0.033)$, ii) advanced tumor stage ( $p=0.047)$, iii) $C A R \geq 0.07$ ( $p=0.011)$, and $i v$ ) postoperative complications $(p=0.028)$ were significant independent predictors of overall survival; moreover, higher carbohydrate antigen levels $(p=0.036)$ and $R 1$ or $R 2$ resection $(p<0.001)$ were significant independent predictors of disease-free survival. Conclusion: Preoperative CAR may be a significant independent predictor of long-term outcomes after GBC resection.
\end{abstract}

Gallbladder carcinoma (GBC) is relatively rarer compared to gastrointestinal carcinoma; however, its incidence is increasing worldwide, and it is considered the most common malignant biliary neoplasm and the seventh-most common type of gastrointestinal cancer (1). Curative resection is the only effective treatment for GBC; however, it is characterized by easy local invasion and lymph node metastasis (2). Most patients with GBC have progressed to the late stage at the time of diagnosis (3). The recurrence rate is high, and GBC is insensitive to radiotherapy and chemotherapy (4), thus, it

This article is freely accessible online.

Correspondence to: Masashi Utsumi, Department of Surgery, National Hospital Organization, Iwakuni Clinical Center, 1-1-1 Atago-machi, Iwakuni-shi, Yamaguchi 740-8510, Japan. Tel: +81 827341000, Fax: +81 827355600, e-mail: masashi11232001@yahoo.co.jp

Key Words: C-reactive protein to albumin ratio, gallbladder carcinoma, Inflammation-based prognostic score. has an extremely poor prognosis. The reported mean survival for patients with GBC ranges from 5.2 to 24.4 months (2-5). For all these reasons, investigating the prognostic factors for GBC is especially important.

There is increasing evidence that the systematic inflammatory response plays an important role in the development of various types of malignancy $(6,7)$. The preoperative systematic inflammation, represented by i) the Glasgow prognostic score (GPS) (8), ii) the neutrophil-tolymphocyte ratio (NLR) (9), iii) the platelet-to-lymphocyte ratio (PLR) (9), and iv) the prognostic nutritional index (PNI) (10) have all been reported to predict cancer-specific survival of GBC. We know that the GPS is based on the circulating levels of two acute phase proteins, i) C-reactive protein (CRP) and ii) albumin. Fairclough E et al. have established the CRP to albumin ratio (CAR), a novel inflammation-based prognostic score based on these two factors, to identify patients with serious illness on acute medical admission, and have reported that it is associated with poor outcomes in patients with sepsis $(11,12)$.

Recently, the prognostic ability of CAR has been reported in patients with i) hepatocellular carcinoma (13), and ii) gastric (14), iii) ovarian (15), iv) colorectal (16), v) esophageal (17), and vi) pancreatic cancers $(18,19)$. In fact, elevated preoperative CAR has been associated with poor survival in patients with the aforementioned cancer types. To our knowledge, the prognostic value of CAR has not been reported in patients with GBC. Therefore, in this study, we retrospectively investigated the relation between preoperative CAR and the overall survival and disease-free survival rates after surgical GBC resection. Moreover, we compared the predictive values of CAR, GPS, NLR, PLR, and PNI.

\section{Patients and Methods}

The study protocol was approved by the Human Ethics Review Committee of Iwakuni Clinical Center (number: 0183). The study was conducted in accordance with the ethical standards of the 1964 Declaration of Helsinki and its later amendments. Informed consent was obtained from all individual participants included in the study (20). 
Table I. Patient characteristics.

\begin{tabular}{lcc}
\hline Variables & Mean \pm SD or rate & Range \\
\hline Age (years) & $73.0 \pm 11.92$ & $38-95$ \\
Gender $(\mathrm{male} / \mathrm{female})$ & $30 / 23$ & \\
BMI $\left(\mathrm{kg} / \mathrm{m}^{2}\right)$ & $21.8 \pm 3.6$ & $15.7-34.7$ \\
Albumin $(\mathrm{g} / \mathrm{dl})$ & $3.84 \pm 0.66$ & $2.0-5.1$ \\
Platelet count $\left(\times 10^{4} / \mathrm{mm}^{3}\right)$ & $25.53 \pm 10.96$ & $10.3-64$ \\
Neutrophil count $\left(\times 10^{3} / \mathrm{mm}^{3}\right)$ & $4.04 \pm 2.32$ & $1.50-16.31$ \\
Lymphocyte count $\left(\times 10^{3} / \mathrm{mm}^{3}\right)$ & $1.47 \pm 0.53$ & $0.64-2.82$ \\
CRP $(\mathrm{mg} / \mathrm{dl})$ & $1.59 \pm 3.38$ & $0.01-18.3$ \\
CEA $(\mathrm{ng} / \mathrm{ml})$ & $4.14 \pm 4.62$ & $0.9-24.9$ \\
CA19-9 $(\mathrm{U} / \mathrm{ml})$ & $223.3 \pm 665.4$ & $2.0-3,633$ \\
ASA $(2 / 3)$ & $39 / 14$ & \\
Associated disease $($ none/present) & $22 / 31$ & \\
Surgical procedure $($ cholecystectomy/ & $(13 / 37 / 3)$ & \\
liver resection/HPD or PD) & & \\
Resection $(\mathrm{R} 0 / \mathrm{R} 1$ or R2) & $41 / 12$ & \\
Duration of operation $(\mathrm{min})$ & $354.5 \pm 188.8$ & $50-908$ \\
Blood loss (ml) & $684.8 \pm 648.2$ & $0-2,638$ \\
Stage UICC 6 6 th $(\mathrm{I} / \mathrm{II} / \mathrm{IIIA} /$ & $11 / 21 / 4 / 10 / 4 / 3$ & \\
IIIB/IVA/VB) & & \\
CAR $(<0.07 / \geq 0.07)$ & $31 / 22$ & \\
GPS $(0 / 1$ or 2$)$ & $32 / 21$ & \\
NLR $(<3.72 / \geq 3.72)$ & $41 / 12$ & \\
PLR $(<0.13 / \geq 0.13)$ & $19 / 34$ & \\
PNI $(<47.9 / \geq 47.9)$ & $28 / 25$ & \\
Postoperative complication & & \\
(Clavien-Dindo $\geq 2)$ None/Present & $33 / 20$ & \\
\hline
\end{tabular}

BMI: Body mass index; CRP: C-reactive protein; CEA: carcinoembryonic; CA19-9: carbohydrate antigen 19-9; ASA: the American Society of Anesthesiologists; UICC: Union for International Cancer Control; HPD: hepatopancreaticoduodenectomy; PD: pancreaticoduodenectomy; CAR: Creactive protein to albumin ratio; GPS: Glasgow prognostic score; NLR: neutrophil-to-lymphocyte ratio; PLR: platelet-to-lymphocyte ratio; PNI: prognostic nutrient index; SD: standard deviation.

Between January 2008 and September 2019, 53 patients with GBC underwent surgical resection at the Iwakuni Clinical Center. Clinical data, tumor characteristics, and survival outcomes were retrospectively reviewed. All participants provided a written informed consent to keep their data in the hospital database, prior to data collection.

We investigated the ways in which clinicopathological variables, such as sex, age, body mass index, associated diseases (hypertension, diabetes, cardiac disease, and stroke), the American Society of Anesthesiologists physical status score, surgical procedure, blood loss, duration of operation, tumor stage according to the Union for International Cancer Control classification, and status of the CAR are related $(21,22)$. We also assessed the overall and disease-free survival rates after surgery using univariate and multivariate analyses by dividing all patients into the high and low CAR groups. Furthermore, we compared the predictive values of CAR, GPS, NLR, PLR, and PNI.

Definition of the inflammation-based prognostic system. Peripheral venous blood samples were collected within 2 weeks before surgery, used for the detection of granulocyte, leukocyte, platelet, albumin,

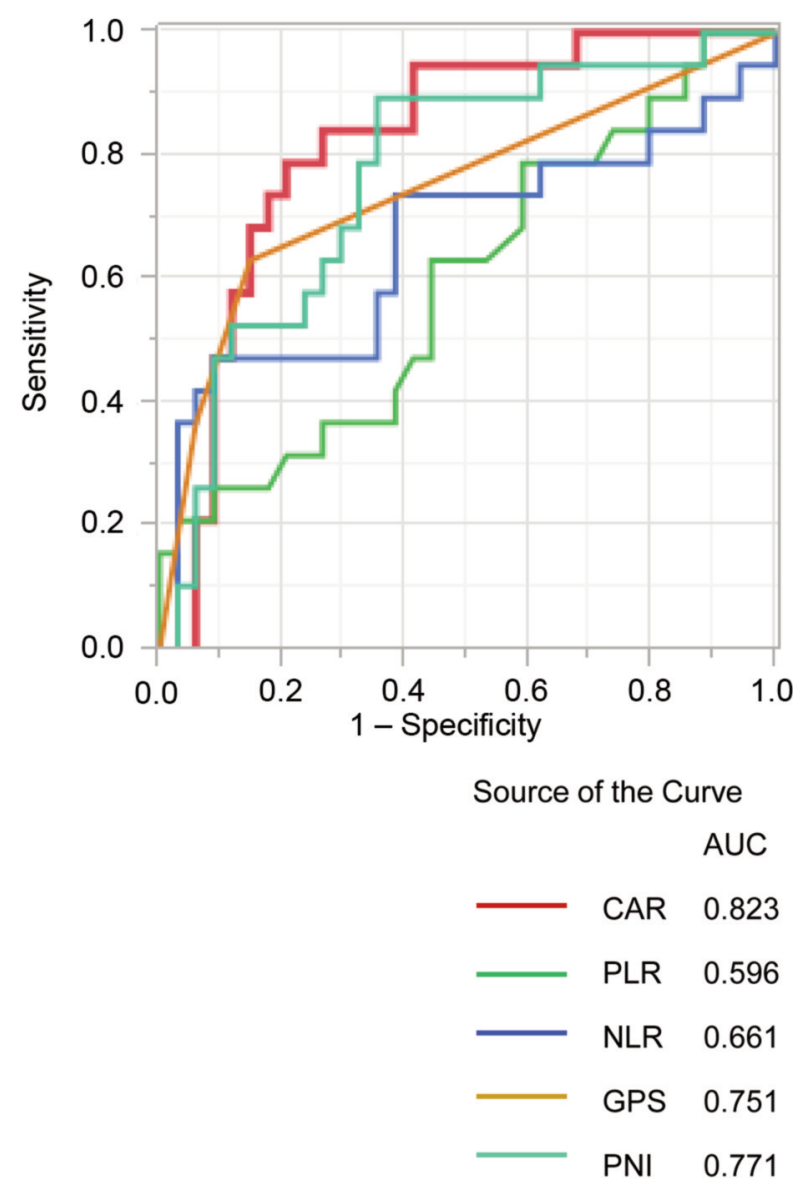

Figure 1. Comparison of areas under the receiver operating characteristic curves for outcome prediction among the five inflammation-based markers. NLR: Neutrophil-to-lymphocyte ratio; PLR: platelet-to-lymphocyte ratio; PNI: prognostic nutrient index; CAR: $C$-reactive protein to albumin ratio; GPS: Glasgow prognostic score.

CRP, carbohydrate antigen (CA19-9), and carcinoembryonic antigen (CEA) levels. From these results we calculated CAR, GPS, NLR, and PLR. CAR was calculated by dividing serum CRP (mg/dl) by serum albumin levels (g/l). GPS was calculated as follows: i) patients with an elevated CRP level $(>1.0 \mathrm{mg} / \mathrm{dl})$ and hypoalbuminemia $(<3.5 \mathrm{~g} / \mathrm{dl})$ were scored as 2 , ii) those who only had one of these biochemical abnormalities as 1 , and those who had no such abnormalities were evaluated with a score of 0 (23). NLR and PLR were calculated by dividing neutrophil and platelet counts by lymphocyte count, respectively $(19,20)$. PNI was calculated according to the following formula: 10xserum albumin $(\mathrm{g} / \mathrm{dl})+0.05 \times$ total lymphocyte count $\left(\right.$ per $\left.\mathrm{mm}^{3}\right)$.

Surgical strategy and follow-up. We applied evidence-based clinical practice guidelines for the treatment of $\operatorname{GBC}(26,27)$. Based on preoperative imaging studies and clinical data, hepatectomy was indicated only in cases in which sufficient hepatic function would have been conserved post-surgery. According to incidental GBC, we used reported treatment strategies (28). Following surgery, all patients were carefully monitored. Tumor marker levels from serum measurements, ultrasonography, and computed tomography were 
Table II. Univariate and multivariate analyses of clinicopathological variables in relation to overall survival after resection of gallbladder carcinoma.

\begin{tabular}{|c|c|c|c|c|}
\hline \multirow[t]{2}{*}{ Variables } & \multicolumn{2}{|c|}{ Univariate analysis } & \multicolumn{2}{|c|}{ Multivariate analysis } \\
\hline & $\mathrm{N}$ & $p$-Value & HR (95\%CI) & $p$-Value \\
\hline \multicolumn{5}{|l|}{ Age (years) } \\
\hline$\geq 75$ & 28 & 0.594 & & \\
\hline$<75$ & 25 & & & \\
\hline \multicolumn{5}{|l|}{ Gender } \\
\hline Male & 30 & 0.152 & & \\
\hline Female & 23 & & & \\
\hline \multicolumn{5}{|l|}{ BMI $\left(\mathrm{kg} / \mathrm{m}^{2}\right)$} \\
\hline$\geq 20$ & 37 & 0.243 & & \\
\hline$<20$ & 16 & & & \\
\hline \multicolumn{5}{|l|}{ CEA (ng/ml) } \\
\hline$\geq 5.2$ & 9 & $<0.001 *$ & 3.926 & 0.173 \\
\hline$<5.2$ & 44 & & $(0.540-28.699)$ & \\
\hline \multicolumn{5}{|l|}{ CA19-9 (U/ml) } \\
\hline$\geq 15.2$ & 29 & $<0.001 *$ & 2.634 & 0.188 \\
\hline$<15.2$ & 24 & & $(0.634-13.959)$ & \\
\hline \multicolumn{5}{|l|}{ ASA } \\
\hline$\geq 3$ & 14 & 0.091 & & \\
\hline$<3$ & 39 & & & \\
\hline \multicolumn{5}{|l|}{ Associated disease } \\
\hline Present & 31 & 0.343 & & \\
\hline None & 21 & & & \\
\hline \multicolumn{5}{|l|}{ Surgical procedure } \\
\hline Cholecystectomy & 13 & 0.648 & & \\
\hline Others & 40 & & & \\
\hline \multicolumn{5}{|l|}{ Resection } \\
\hline R0 & 41 & $<0.001 *$ & 4.860 & $0.033^{*}$ \\
\hline $\mathrm{R} 1$ or $\mathrm{R} 2$ & 12 & & $(1.137-22.285)$ & \\
\hline \multicolumn{5}{|c|}{ Duration of operation (min) } \\
\hline$\geq 300$ & 33 & 0.836 & & \\
\hline$<300$ & 19 & & & \\
\hline \multicolumn{5}{|l|}{ Blood loss (ml) } \\
\hline$\geq 500$ & 27 & 0.307 & & \\
\hline$<500$ & 25 & & & \\
\hline \multicolumn{5}{|l|}{ Tumour stage (UICC) } \\
\hline 3 or 4 & 20 & $<0.001^{*}$ & 3.807 & $0.047^{*}$ \\
\hline 1 or 2 & 33 & & $(1.018-15.807)$ & \\
\hline \multicolumn{5}{|l|}{ CAR } \\
\hline$\geq 0.07$ & 22 & $<0.001 *$ & 8.849 & $0.011 *$ \\
\hline$<0.07$ & 31 & & $(1.640-53.113)$ & \\
\hline \multicolumn{5}{|l|}{ GPS } \\
\hline 1 or 2 & 17 & $<0.001 *$ & 4.201 & 0.230 \\
\hline 0 & 36 & & $(0.384-41.692)$ & \\
\hline \multicolumn{5}{|l|}{ NLR } \\
\hline$\geq 3.72$ & 12 & $<0.001^{*}$ & 2.084 & 0.473 \\
\hline$<3.72$ & 41 & & $(0.278-16.499)$ & \\
\hline \multicolumn{5}{|l|}{ PLR } \\
\hline$\geq 127$ & 34 & 0.211 & & \\
\hline$<127$ & 19 & & & \\
\hline PNI & & & & \\
\hline$<47.9$ & 28 & $<0.001 *$ & 1.354 & 0.723 \\
\hline$\geq 47.9$ & 25 & & $(0.253-8.372)$ & \\
\hline $\begin{array}{l}\text { Postoperative compl } \\
\text { (Clavien-Dindo } \geq 2)\end{array}$ & & & & \\
\hline None & 33 & $0.002 *$ & 4.511 & $0.028^{*}$ \\
\hline Present & 20 & & $(1.174-19.939)$ & \\
\hline
\end{tabular}

HR: Hazard ratio; CI: confidence interval; BMI: body mass index; CRP: C-reactive protein; CEA: carcinoembryonic; CA19-9: carbohydrate antigen 19-9; ASA: the American Society of Anesthesiologists; UICC: Union for International Cancer Control; CAR: C-reactive protein to albumin ratio; GPS: Glasgow prognostic score; NLR: neutrophil-tolymphocyte ratio; PLR: platelet-to-lymphocyte ratio; PNI: prognostic nutrient index; SD: standard deviation. *Statistically significant. conducted every 3 months. The follow-up period ended in the last follow-up visit (February 2020) or in case of death. At the time of manuscript preparation, the median follow-up time of surviving patients was 34 (range $=1-130$ ) months.

Complications were defined according to the method described by Clavien et al. (29). In this study, postoperative complications were defined as complications that were grade 2 or higher, while postoperative mortality was defined as any death incident occurring within 30 days post-surgery.

Statistical analysis. Data are expressed as mean \pm standard deviation (SD). Univariate analysis was performed using the Mann-Whitney U and the Chi-square tests. Diagnostic accuracy was determined by the area under the receiver operating characteristic curve (ROC). The optimal cut-off values of CAR, NLR, GPS, PLR, and PNI were determined by maximizing the Youden index (sensitivity+ specificity-1) (30). The Kaplan-Meier method was used to analyze the overall and disease-free survival rates while the log-rank test was used to compare differences between the subgroups. Univariate and multivariate analyses were performed for the prognostic factors using the Cox proportional hazard model, as significant different variables analyzed by the univariate analysis were further analyzed by the multiple Cox proportional hazards model. The statistical significance level was set at $p<0.05$ in all analyses. Statistical analysis was performed using JMP version 9 (SAS Institute, Cary, NC, USA).

\section{Results}

Patient characteristics. Fifty-three patients were enrolled in this study [mean age $=73.0 \pm 11.92$ years (range $=38-95$ ), sex $=30$ men and 23 women]. Patient characteristics are outlined in Table I. Operative procedures consisted of: i) cholecystectomy (13 patients), ii) liver bed resection (6 patients), iii) hepatic resection of segments $4 \mathrm{~b}$ and 5 (26 patients), iv) extended right lobectomy (5 patients), v) hepatopancreaticoduodenectomy (3 patients), and vi) pancreaticoduodenectomy (one patient). Postoperative complications developed in 20 of 51 patients; these included: i) bile leakage (10 patients), ii) surgical site infection (two patients), iii) pancreatic fistula (two patients), iv) abdominal abscess (two patients), v) ileus (two patients), vi) chylous ascites (one patient), and vii) acute respiratory distress syndrome (one patient).

ROC analysis. Using the overall survival rate as an endpoint, the optimal cut-off value for inflammation-based markers was determined using the area under the curve (AUC) of ROC curves: i) $\mathrm{CAR}=0.07$ ( $\mathrm{AUC}=0.823$ ), ii) $\mathrm{PNI}=47.9$ (AUC $=0.771$ ), iii) $\mathrm{GPS}=1$ ( $\mathrm{AUC}=0.751)$, iv) $\mathrm{NLR}=3.72$ (AUC $=0.661)$, and v) PLR $=0.13$ (AUC=0.596). The CAR value was the highest (statistically significant) among the inflammation-based markers (Figure 1).

Univariate and multivariate analyses of the clinicopathological variables in relation to overall survival after surgical GBC resection. The 1-, 3-, and 5-year overall 


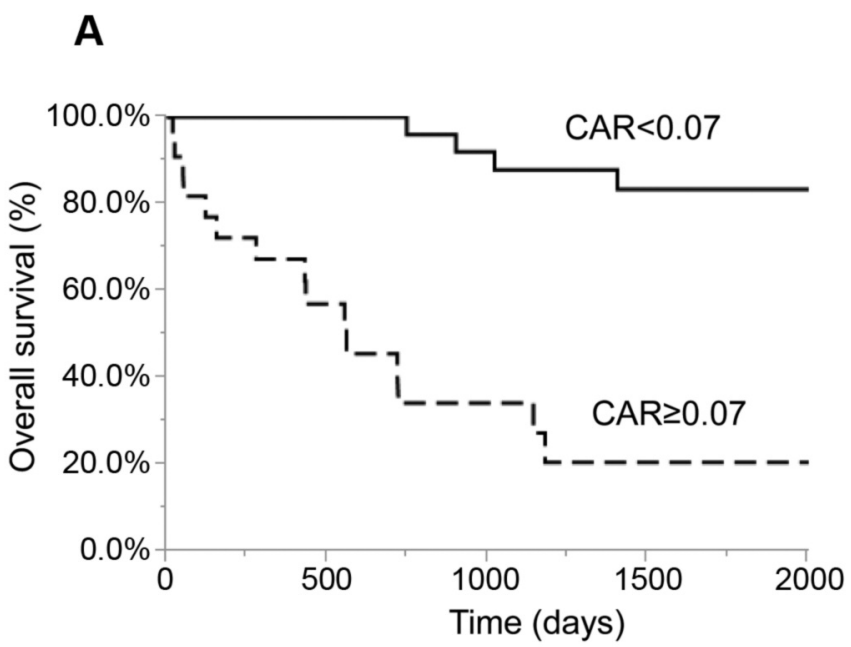

\section{B}

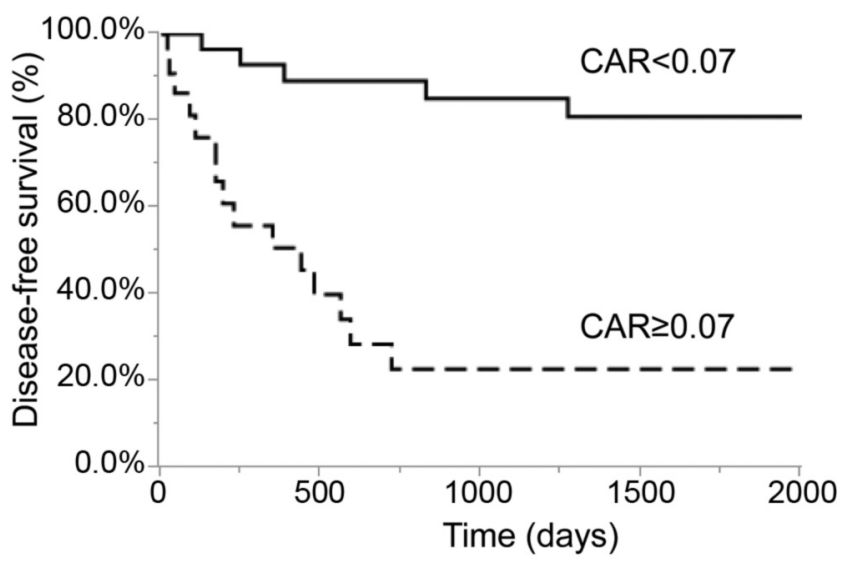

Figure 2. Relationship of the C-reactive protein to albumin ratio with overall survival (a) and disease-free survival (b). NLR: Neutrophil-tolymphocyte ratio; PLR: platelet-to-lymphocyte ratio; PNI: prognostic nutrient index; CAR: C-reactive protein to albumin ratio; GPS: Glasgow prognostic score.

survival rates were $84.1,65.4$, and $57.6 \%$, respectively. Table II shows the relationship between the clinicopathological variables and the overall survival rates following surgical GBC resection. In the univariate analysis, the overall survival was significantly worse in patients with increased CEA levels $(p<0.001), \mathrm{CA} 19-9(p<0.001), \mathrm{R} 1$ or R2 resection $(p<0.001)$, tumor stage 3 or $4(p<0.001), \mathrm{CAR} \geq 0.07(p<0.001$, Figure $2 \mathrm{a})$, GPS 1 or $2(p<0.001), \mathrm{NLR} \geq 3.72(p<0.001), \mathrm{PNI}<47.9$ $(p<0.001)$, and postoperative complications $(p=0.002)$. In the multivariate analysis, $\mathrm{R} 1$ or $\mathrm{R} 2$ resection $(p=0.033)$, tumor stage 3 or $4 \quad(p=0.047), \quad \mathrm{CAR} \geq 0.07 \quad(p=0.011)$, and postoperative complications $(p=0.028)$ were independent and significant predictors of overall survival.

Univariate and multivariate analyses of the clinicopathological variables in relation to disease-free survival following surgical GBC resection. Table III shows the relationship between the clinicopathological variables and the diseasefree survival following surgical GBC resection. In the univariate analysis, disease-free survival was significantly worse in patients with higher CEA levels $(p=0.006)$, CA19$9(p<0.001), \mathrm{R} 1$ or $\mathrm{R} 2$ resection $(p<0.001)$, tumor stage 3 or $4(p<0.001), \mathrm{CAR} \geq 0.07(p<0.001$, Figure $2 \mathrm{~b})$, GPS 1 or 2 $(p<0.001), \mathrm{NLR} \geq 3.72(p=0.001), \mathrm{PNI}<47.9(p=0.002)$, and postoperative complications $(p=0.008)$. In the multivariate analysis, higher levels of CA19-9 $(p=0.036)$ and R1 or R2 resection $(p<0.001)$ were independent and significant predictors of disease-free survival.

Association between the clinicopathologic variables and the $C A R$. Table IV shows the relationship between the clinicopathologic variables and the CAR. Patients with
$\mathrm{CAR} \geq 0.07$ have i) significantly longer duration of operation $(p<0.001)$, ii) greater blood loss $(p<0.001)$, iii) more advanced tumor stage $(p=0.014)$, iv) higher CEA levels $(p=0.025)$, and v) more postoperative complications $(p<0.001)$ compared to those with $\mathrm{CAR}<0.07$. Additionally, the CAR was associated with other inflammatory markers, including GPS $(p<0.001)$, NLR $(p<0.001)$, PLR $(p=0.003)$, and PNI $(p<0.001)$.

\section{Discussion}

This study demonstrated that non-curative resection, advanced tumor stage, elevated CAR, and postoperative complications were independent prognostic factors of poor survival following GBC resection. Elevated CA19-9 and non-curative resection were independent predictors of worse recurrence-free survival. Moreover, only the CAR was evaluated as an independent preoperative prognostic factor. Conversely, the other established inflammation-based prognostic scores in the multivariate analysis, such as GPS, NLR, PLR, and PNI, were poor independent prognostic factors. Consequently, we compared CAR's prognostic ability to the other inflammation-based prognostic scores, and found that in the context of GBC, the AUC of the CAR was superior to other scores in terms of predictive accuracy. These results are consistent with previous studies identifying the CAR as an outcome predictor of hepatocellular carcinoma (13), as well as of gastric (14), ovarian (15), colorectal (16), and pancreatic cancer $(18,19)$.

Furthermore, we noted that an increased CAR was significantly correlated with i) an advanced stage, ii) increased CEA, iii) longer duration of operation, iv) greater blood loss, and v) postoperative complications, suggesting 
Table III. Univariate and multivariate analyses of clinicopathological variables in relation to disease-free survival after resection of gallbladder carcinoma.

\begin{tabular}{|c|c|c|c|c|}
\hline \multirow[t]{2}{*}{ Variables } & \multicolumn{2}{|c|}{ Univariate analysis } & \multicolumn{2}{|c|}{ Multivariate analysis } \\
\hline & $\mathrm{N}$ & $p$-Value & $\mathrm{HR}(95 \% \mathrm{CI})$ & $p$-Value \\
\hline \multicolumn{5}{|l|}{ Age (years) } \\
\hline$\geq 75$ & 28 & 0.511 & & \\
\hline$<75$ & 25 & & & \\
\hline \multicolumn{5}{|l|}{ Gender } \\
\hline Male & 30 & 0.343 & & \\
\hline Female & 23 & & & \\
\hline \multicolumn{5}{|l|}{ BMI $\left(\mathrm{kg} / \mathrm{m}^{2}\right)$} \\
\hline$\geq 20$ & 37 & 0.412 & & \\
\hline$<20$ & 16 & & & \\
\hline \multicolumn{5}{|l|}{ CEA (ng/ml) } \\
\hline$\geq 5.2$ & 9 & $0.006^{*}$ & 4.55 & 0.077 \\
\hline$<5.2$ & 44 & & $0.848-24.900$ & \\
\hline \multicolumn{5}{|l|}{ CA19-9 (U/ml) } \\
\hline$\geq 15.2$ & 29 & $<0.001 *$ & 4.45 & $0.036^{*}$ \\
\hline$<15.2$ & 24 & & $1.095-24.298$ & \\
\hline \multicolumn{5}{|l|}{ ASA } \\
\hline$\geq 3$ & 14 & 0.272 & & \\
\hline$<3$ & 39 & & & \\
\hline \multicolumn{5}{|l|}{ Associated disease } \\
\hline Present & 31 & 0.099 & & \\
\hline None & 21 & & & \\
\hline \multicolumn{5}{|l|}{ Surgical procedure } \\
\hline Cholecystectomy & 13 & 0.920 & & \\
\hline Others & 40 & & & \\
\hline \multicolumn{5}{|l|}{ Resection } \\
\hline R0 & 41 & $<0.001 *$ & 15.943 & $<0.001 *$ \\
\hline $\mathrm{R} 1$ or $\mathrm{R} 2$ & 12 & & $3.400-81.103$ & \\
\hline \multicolumn{5}{|c|}{ Duration of operation (min) } \\
\hline$\geq 300$ & 33 & 0.661 & & \\
\hline$<300$ & 19 & & & \\
\hline \multicolumn{5}{|l|}{ Blood loss (ml) } \\
\hline$\geq 500$ & 27 & 0.273 & & \\
\hline$<500$ & 25 & & & \\
\hline \multicolumn{5}{|l|}{ Tumour stage (UICC) } \\
\hline 3 or 4 & 20 & $<0.001 *$ & 1.504 & 0.547 \\
\hline 1 or 2 & 33 & & $0.396-5.920$ & \\
\hline \multicolumn{5}{|l|}{ CAR } \\
\hline$\geq 0.07$ & 22 & $<0.001 *$ & 3.296 & 0.192 \\
\hline$<0.07$ & 31 & & $0.558-23.575$ & \\
\hline \multicolumn{5}{|l|}{ GPS } \\
\hline 1 or 2 & 17 & $<0.001 *$ & 0.973 & 0.977 \\
\hline 0 & 36 & & $0.145-6.051$ & \\
\hline \multicolumn{5}{|l|}{ NLR } \\
\hline$\geq 3.72$ & 12 & $0.001 *$ & 1.846 & 0.454 \\
\hline$<3.72$ & 41 & & $0.346-8.762$ & \\
\hline \multicolumn{5}{|l|}{ PLR } \\
\hline$\geq 127$ & 34 & 0.444 & & \\
\hline$<127$ & 19 & & & \\
\hline PNI & & & & \\
\hline$<47.9$ & 28 & $0.002 *$ & 1.923 & 0.376 \\
\hline$\geq 47.9$ & 25 & & $0.448-8.951$ & \\
\hline $\begin{array}{r}\text { Postoperative comp } \\
\text { (Clavien-Dindo } \geq 2)\end{array}$ & & & & \\
\hline None & 33 & $0.008 *$ & 1.295 & 0.689 \\
\hline Present & 20 & & $0.363-4.715$ & \\
\hline
\end{tabular}

HR: Hazard ratio; CI: confidence interval; BMI: body mass index; CRP: C-reactive protein; CEA: carcinoembryonic; CA19-9: carbohydrate antigen 19-9; ASA: the American Society of Anesthesiologists; UICC: Union for International Cancer Control; CAR: C-reactive protein to albumin ratio; GPS: Glasgow prognostic score; NLR: neutrophil-tolymphocyte ratio; PLR: platelet-to-lymphocyte ratio; PNI: prognostic nutrient index; SD: standard deviation. *Statistically significant.
Table IV. Univariate and multivariate analyses of clinicopathological variables in relation to $C$-reactive protein to albumin ratio.

\begin{tabular}{|c|c|c|c|}
\hline Variables & $\begin{array}{c}\text { CAR }<0.07 \\
(\mathrm{n}=31)\end{array}$ & $\begin{array}{c}\mathrm{CAR} \geq 0.07 \\
(\mathrm{n}=22)\end{array}$ & $\begin{array}{l}\text { Univariate } \\
\text { analysis }\end{array}$ \\
\hline Age (years) & $73.0 \pm 13.3$ & $72.9 \pm 10.1$ & 0.989 \\
\hline Sex (male/female) & $15 / 16$ & $15 / 7$ & 0.149 \\
\hline $\operatorname{BMI}\left(\mathrm{kg} / \mathrm{m}^{2}\right)$ & $22.28 \pm 3.49$ & $21.11 \pm 3.70$ & 0.246 \\
\hline $\begin{array}{l}\text { Associated disease } \\
\text { (none/present) }\end{array}$ & $10 / 21$ & $12 / 10$ & 0.105 \\
\hline $\begin{array}{l}\text { Surgical procedure } \\
\text { (Cholecystectomy/Others) }\end{array}$ & $9 / 22$ & $4 / 18$ & 0.359 \\
\hline Resection (R0/R1 or R2) & $26 / 5$ & $15 / 7$ & 0.181 \\
\hline Duration of operation (min) & $281.8 \pm 31.0$ & $453.8 \pm 36.2$ & $<0.001 *$ \\
\hline Blood loss (ml) & $402.3 \pm 107.4$ & $1044.4 \pm 121.2$ & $<0.001 *$ \\
\hline \multicolumn{4}{|l|}{ Tumour stage (UICC) } \\
\hline 1 or $2 / 3$ or 4 & $10 / 21$ & $1 / 21$ & $0.014 *$ \\
\hline CEA (ng/ml) & $2.95 \pm 1.52$ & $5.82 \pm 6.67$ & $0.025^{*}$ \\
\hline CA19-9 (U/ml) & $216.8 \pm 690.7$ & $232.8 \pm 642.8$ & 0.933 \\
\hline $\operatorname{ASA}(2 / 3)$ & $24 / 7$ & $15 / 7$ & 0.454 \\
\hline GPS $(0 / 1$ or 2$)$ & $30 / 1$ & $6 / 16$ & $<0.001 *$ \\
\hline $\operatorname{NLR}(<3.72 / \geq 3.72)$ & $30 / 1$ & $11 / 11$ & $<0.001 *$ \\
\hline $\operatorname{PLR}(<0.13 / \geq 0.13)$ & $16 / 15$ & $3 / 19$ & $0.003 *$ \\
\hline PNI $(<47.9 / \geq 47.9)$ & $9 / 22$ & $3 / 19$ & $<0.001 *$ \\
\hline \multicolumn{4}{|l|}{$\begin{array}{l}\text { Postoperative complication } \\
\text { (Clavien-Dindo } \geq 2 \text { ) }\end{array}$} \\
\hline None/Present & $25 / 6$ & $8 / 14$ & $<0.001 *$ \\
\hline
\end{tabular}

HR: Hazard ratio; CI: confidence interval; BMI: body mass index; CRP: C-reactive protein; CEA: carcinoembryonic; CA19-9: carbohydrate antigen 19-9; ASA: the American Society of Anesthesiologists; UICC: Union for International Cancer Control; CAR: C-reactive protein to albumin ratio; GPS: Glasgow prognostic score; NLR: neutrophil-tolymphocyte ratio; PLR: platelet-to-lymphocyte ratio; PNI: prognostic nutrient index; SD: standard deviation. *Statistically significant.

that it may be correlated with more aggressive surgery and disease phenotype.

The association between inflammation and cancer is based on the observation that tumors often arise on chronic inflammation sites and that inflammatory cells are present in biopsied samples collected from tumor tissues (31). In the case of GBC, chronic cholecystitis resulting from gallbladder stones or bacterial infection is thought to be a major oncogenic driver (32). Moreover, recent clinical and laboratory studies have indicated that inflammation is closely related to cancer progression and metastasis, and an inflammatory microenvironment has even been proposed as the seventh hallmark of cancer (33-35). Therefore, inflammation markers might predict the prognosis of various cancers, including GBC.

Currently, the correlational mechanism between the CAR and cancer-specific survival remains unclear. Elevated serum CRP levels reflect a non-specific inflammatory response to tumor necrosis or local tissue damage, and indicate a favorable environment for the establishment and growth of distant metastasis (36). In this study, patients with advanced 
tumor stage had an elevated CAR, potentially reflecting these factors. Xavier et al. have reported that Serum CRP inhibits apoptosis of cancer cells in a myeloma setting to determine whether CRP affects tumor cell growth and survival (37). Fondevila et al. have reported that serum levels of vascular endothelial growth factors (angiogenic factors) increase in the presence of elevated serum CRP concentration (38).

In addition, hypoalbuminemia is often observed in patients with advanced cancer and is regarded as a marker of malnutrition (39). Also, serum albumin participates in the systemic inflammatory response and its reduced levels are associated with poor long-term survival in patients with various cancers (40).

The CAR may reflect a systemic inflammatory response and the progressive nutritional decline, resulting in poor survival. Perioperative nutritional support was recommended to improve the nutritional status in patients with hepatobiliarypancreatic carcinoma, as there was a high prevalence of malnutrition (41). Indeed, preoperative immunonutrition has been reported to suppress the perioperative inflammatory response (42). Further investigation to evaluate the relationship between immunonutrition and this inflammatorybased prognostic score is important to improve the management of patients with GBC.

To the best of our knowledge, this is the first study to investigate whether the CAR is useful for predicting postoperative outcomes in GBC. Survival following surgical resection for patients with GBC greatly depends on disease stage and whether curative resection is achieved; however, these can only be properly evaluated postoperatively. Our results suggest that the preoperative CAR might potentially serve as a clinically valuable marker in patients with GBC. The CAR has the advantage of being easily measured, routinely available, and well-standardized. Moreover, an increased CAR might be correlated with a more aggressive form of disease, thereby making it possible to use it for screening a subset of patients with bad prognosis who require intense treatment. Additionally, the CAR displayed an improved prognostic ability compared to the other inflammation-based scoring systems and may be a complementary factor for defining tumor stage in predicting survival in patients with GBC.

Our study had limitations, as it was a retrospective singlecentre study with a small sample size. Prospective cohort studies in multiple institutions should be performed to confirm these results.

In conclusion, our study showed that the CAR may be an independent and significant indicator of poor long-term outcome in patients with GBC following surgery.।

\section{Conflicts of Interest}

The Authors declare that they have no conflicts of interest.

\section{Authors' Contributions}

MU, HA, SN, SN, YU, YK, MW, FT, TA, KK and KT designed the study. HA, MU and YK treated and observed the patients. MU prepared the manuscript and performed the literature search. HA corrected and revised the manuscript. All Authors read and approved the final manuscript.

\section{References}

1 Donohue JH, Stewart AK and Menck HR: The National Cancer Data Base report on carcinoma of the gallbladder, 1989-1995. Cancer 83(12): 2618-2628, 1998. PMID: 9874470. DOI: 10.1002/(sici)1097-0142(19981215)83:12<2618::aidcncr29>3.0.co;2-h

2 Butte JM, Matsuo K, Gonen M, D'Angelica MI, Waugh E, Allen PJ, Fong Y, DeMatteo RP, Blumgart L, Endo I, De La Fuente H and Jarnagin WR: Gallbladder cancer: differences in presentation, surgical treatment, and survival in patients treated at centers in three countries. J Am Coll Surg 212(1): 50-61, 2011. PMID: 21075015. DOI: 10.1016/j.jamcollsurg.2010.09.009

3 Miller G and Jarnagin WR: Gallbladder carcinoma. Eur J Surg Oncol 34(3): 306-312, 2008. PMID:17964753. DOI: 10.1016/ j.ejso.2007.07.206

4 Bartlett DL, Fong Y, Fortner JG, Brennan MF and Blumgart LH: Long-term results after resection for gallbladder cancer. Implications for staging and management. Ann Surg 224(5): 639-646, 1996. PMID: 20495633. DOI: 10.1111/j.1477-2574. 2009.00108.x

5 Cziupka K, Partecke LI, Mirow L, Heidecke CD, Emde C, Hoffmann W, Siewert U, van den Berg N, von Bernstorff W and Stier A: Outcomes and prognostic factors in gallbladder cancer: a single-centre experience. Langenbecks Arch Surg 397(6): 899907, 2012. PMID: 22454256. DOI: 10.1007/s00423-012-0950-8

6 Mantovani A, Allavena P, Sica A and Balkwill F: Cancer-related inflammation. Nature 454(7203): 436-444, 2008. PMID: 18650914. DOI: 10.1038 /nature07205

7 Pages F, Galon J, Dieu-Nosjean MC, Tartour E, Sautès-Fridman $\mathrm{C}$ and Fridman WH: Immune infiltration in human tumors: a prognostic factor that should not be ignored. Oncogene 29(8): 1093-1102, 2010. PMID: 19946335. DOI: 10.1038/onc. 2009.416

8 Shiba H, Misawa T, Fujiwara Y, Futagawa Y, Furukawa K, Haruki K, Iwase R, Iida T and Yanaga K: Glasgow prognostic score predicts outcome after surgical resection of gallbladder cancer. World J Surg 39(3): 753-758, 2015. PMID: 25348884. DOI: $10.1007 / \mathrm{s} 00268-014-2844-0$

9 Zhang Y, Jiang C, Li J, Sun J and Qu X: Prognostic significance of preoperative neutrophil/lymphocyte ratio and platelet/lymphocyte ratio in patients with gallbladder carcinoma. Clin Transl Oncol 17(10): 810-818, 2015. PMID: 26077119. DOI: $10.1007 / \mathrm{s} 12094-015-1310-2$

10 Deng Y, Pang Q, Bi JB, Zhang X, Zhang LQ, Zhou YY, Miao $\mathrm{RC}$, Chen W, Qu K and Liu C: A promising prediction model for survival in gallbladder carcinoma patients: pretreatment prognostic nutrient index. Tumour Biol, 2016. PMID: 27722987. DOI: $10.1007 / \mathrm{s} 13277-016-5396-0$

11 Fairclough E, Cairns E, Hamilton J and Kelly C: Evaluation of a modified early warning system for acute medical admissions and comparison with C-reactive protein/albumin 
ratio as a predictor of patient outcome. Clin Med (Lond) 9(1): 30-33, 2009. PMID: 23555017. DOI: 10.1371/journal.pone. 0059321

12 Ranzani OT, Zampieri FG, Forte DN, Azevedo LC and Park M: C-reactive protein/albumin ratio predicts 90-day mortality of septic patients. PloS One 8(3): e59321, 2013. PMID: 23555017. DOI: 10.1371 /journal.pone.0059321

13 Kinoshita A, Onoda H, Imai N, Iwaku A, Oishi M, Tanaka K, Fushiya N, Koike K, Nishino H and Matsushima M: The Creactive protein/albumin ratio, a novel inflammation-based prognostic score, predicts outcomes in patients with hepatocellular carcinoma. Ann Surg Oncol 22(3): 803-810, 2015. PMID: 25190127. DOI: 10.1245/s10434-014-4048-0

14 Liu X, Sun X, Liu J, Kong P, Chen S, Zhan Y and Xu D: Preoperative C-reactive protein/albumin ratio predicts prognosis of patients after curative resection for gastric cancer. Transl Oncol 8(4): 339-345, 2015. PMID: 26310380. DOI: 10.1245/ s10434-014-4048-0.

15 Liu Y, Chen S, Zheng C, Ding M, Zhang L, Wang L, Xie M and Zhou J: The prognostic value of the preoperative c-reactive protein/albumin ratio in ovarian cancer. BMC Cancer 17(1): 285, 2017. PMID: 28431566. DOI: 10.1186/s12885-017-3220-x

16 Shibutani M, Maeda K, Nagahara H, Iseki Y, Ikeya $\mathrm{T}$ and Hirakawa K: Prognostic significance of the preoperative ratio of C-reactive protein to albumin in patients with colorectal cancer. Anticancer Res 36(3): 995-1001, 2016. PMID: 26976989.

17 Sakai M, Sohda M, Saito H, Ubukata Y, Nakazawa N, Kuriyama K, Hara K, Sano A, Ogata K, Yokobori T, Shirabe K and Saeki $\mathrm{H}$ : Comparative analysis of immunoinflammatory and nutritional measures in surgically resected esophageal cancer: A singlecenter retrospective study. In Vivo 34(2): 881-887, 2020. PMID: 32111799. DOI: 10.21873/invivo.11853

18 Haruki K, Shiba H, Shirai Y, Horiuchi T, Iwase R, Fujiwara Y, Furukawa $\mathrm{K}$, Misawa $\mathrm{T}$ and Yanaga $\mathrm{K}$ : The $\mathrm{C}$-reactive protein to albumin ratio predicts long-term outcomes in patients with pancreatic cancer after pancreatic resection. World J Surg 40(9): 2254-2260, 2016. PMID: 26956901. DOI: 10.1007/s00268-0163491-4

19 Vujic J, Marsoner K, Wienerroither V, Mischinger HJ and Kornprat P: The predictive value of the crp-to-albumin ratio for patients with pancreatic cancer after curative resection: A retrospective single center study. In Vivo 33(6): 2071-2078, 2019. PMID: 31662540 . DOI: 10.21873 /invivo. 11706

20 Rits IA: Declaration of helsinki. Recommendations guidings doctors in clinical research. World Med J 11: 281, 1964. PMID: 14182999.

21 Rozner MA: The american society of anesthesiologists physical status score and risk of perioperative infection. JAMA 275(20): 1544, 1996. PMID: 8622238.

22 Brierley JD, Gospodarowicz MK, Wittekind C, editors: UICC TNM Classification of Malignant Tumours. $8^{\text {th }}$ edition. Wiley Blackwell; New York, NY: 2017.

23 Forrest LM, McMillan DC, McArdle CS, Angerson WJ and Dunlop DJ: Evaluation of cumulative prognostic scores based on the systemic inflammatory response in patients with inoperable non-small-cell lung cancer. Br J Cancer 89(6): 10281030, 2003. PMID: 12966420. DOI: 10.1038/sj.bjc.6601242

24 Zahorec R: Ratio of neutrophil to lymphocyte counts-rapid and simple parameter of systemic inflammation and stress in critically ill (in English, Slovak). Bratisl Lek Listy 102(1): 5-14, 2001. PMID: 11723675.

25 Josse JM, Cleghorn MC, Ramji KM, Jiang H, Elnahas A, Jackson TD, Okrainec A and Quereshy FA: The neutrophil-tolymphocyte ratio predicts major perioperative complications in patients undergoing colorectal surgery. Colorectal Dis 18(7): O236-242, 2016. PMID: 27154050. DOI: 10.1111/codi.13373

26 Miyazaki M, Yoshitomi H, Miyakawa S, Uesaka K, Unno M, Endo I, Ota T, Ohtsuka M, Kinoshita H, Shimada K, Shimizu H, Tabata M, Chijiiwa K, Nagino M, Hirano S, Wakai T, Wada K, Isayama $\mathrm{H}$, Okusaka T, Tsuyuguchi T, Fujita N, Furuse J, Yamao K, Murakami K, Yamazaki H, Kijima H, Nakanuma Y, Yoshida M, Takayashiki T and Takada T: Clinical practice guidelines for the management of biliary tract cancers 2015: the $2^{\text {nd }}$ English edition. J Hepatobiliary Pancreat Sci 22(4): 249-273, 2015. PMID: 25787274. DOI: $10.1002 /$ jhbp. 233

27 Takada T: Clinical practice guidelines for the management of biliary tract and ampullary carcinomas. J Hepatobiliary Pancreat Surg 15(1): 1, 2008. PMID: 18274837. DOI: 10.1007/s00534$007-1273-y$

28 Utsumi M, Aoki H, Kunitomo T, Mushiake Y, Yasuhara I, Arata T, Katsuda K, Tanakaya K and Takeuchi H: Evaluation of surgical treatment for incidental gallbladder carcinoma diagnosed during or after laparoscopic cholecystectomy: single center results. BMC Res Notes 10(1): 56, 2017. PMID: 28109315. DOI: 10.1186/s13104-017-2387-1

29 Clavien PA, Barkun J, de Oliveira ML, Vauthey JN, Dindo D, Schulick RD, de Santibañes E, Pekolj J, Slankamenac K, Bassi C, Graf R, Vonlanthen R, Padbury R, Cameron JL and Makuuchi M: The Clavien-Dindo classification of surgical complications: five-year experience. Ann Surg 250(2): 187-196, 2009. PMID: 19638912. DOI: $10.1097 /$ SLA.0b013e3181b13ca2

30 Youden WJ: Index for rating diagnostic tests: Cancer 3(1): 32 35, 1950. PMID: 15405679. DOI: 10.1002/1097-0142(1950)3: $1<32$ ::aid-cncr2820030106>3.0.co;2-3

31 Kinoshita A, Onoda H, Imai N, Iwaku A, Oishi M, Tanaka K, Fushiya N, Koike K, Nishino H, Matsushima M, Saeki C and Tajiri H: The Glasgow Prognostic Score, an inflammation based prognostic score, predicts survival in patients with hepatocellular carcinoma. BMC Cancer 13: 52, 2013. PMID: 23374755. DOI: 10.1186/1471-2407-13-52

32 Wu XS, Shi LB, Li ML, Ding Q, Weng H, Wu WG, Cao Y, Bao RF, Shu YJ, Ding QC, Mu JS, Gu J, Dong P and Liu YB: Evaluation of two inflammation-based prognostic scores in patients with resectable gallbladder carcinoma. Ann Surg Oncol 21(2): 449-457, 2014. PMID: 24081806. DOI: 10.1245/s10434013-3292-z

33 Qian BZ, Li J, Zhang H, Kitamura T, Zhang J, Campion LR, Kaiser EA, Snyder LA and Pollard JW: CCL2 recruits inflammatory monocytes to facilitate breast-tumour metastasis. Nature 475(7355): 222-225, 2011. PMID: 21654748. DOI: 10.1038 /nature 10138

34 Coussens LM and Werb Z: Inflammation and cancer. Nature 420(6917): 860-867, 2002. PMID: 12490959. DOI: 10.1038/ nature 01322

35 Mantovani A: Cancer: Inflaming metastasis. Nature 457(7225): 36-37, 2009. PMID: 19122629. DOI: 10.1038/457036b

36 Wong VK, Malik HZ, Hamady ZZ, Al-Mukhtar A, Gomez D, Prasad KR, Toogood GJ and Lodge JP: C-reactive protein as a predictor of prognosis following curative resection for colorectal 
liver metastases. Br J Cancer 96(2): 222-225, 2007. PMID: 17211465. DOI:10.1038/sj.bjc.6603558

37 Xavier P, Belo L, Beires J, Rebelo I, Martinez-de-Oliveira J, Lunet N and Barros H: Serum levels of VEGF and TNF-alpha and their association with C-reactive protein in patients with endometriosis. Arch Gynecol Obstet 273(4): 227-231, 2006. PMID: 16208475. DOI: 10.1007/s00404-005-0080-4 .

38 Fondevila C, Metges JP, Fuster J, Grau JJ, Palacín A, Castells A, Volant A and Pera M: p53 and VEGF expression are independent predictors of tumour recurrence and survival following curative resection of gastric cancer. Br J Cancer 90(1): 206-215, 2004. PMID: 14710231. DOI: 10.1038/sj.bjc.6601455

39 Valenzuela-Landaeta K, Rojas P and Basfi-fer K: [Nutritional assessment for cancer patient]. Nutr Hosp 27(2): 516-523, 2012. PMID: 22732977. DOI: 10.1590/S0212-16112012000200025

40 McMillan DC, Elahi MM, Sattar N, Angerson WJ, Johnstone J and McArdle CS: Measurement of the systemic inflammatory response predicts cancer-specific and non-cancer survival in patients with cancer. Nutr Cancer 41(1-2): 64-69, 2001. PMID:12094630 DOI:10.1080/01635581.2001.9680613
41 Bozzetti F and Mariani L: Perioperative nutritional support of patients undergoing pancreatic surgery in the age of ERAS. Nutrition 30: 1267-1271, 2014. PMID: 24973198. DOI: 10.1016/ j.nut.2014.03.002

42 Uno H, Furukawa K, Suzuki D, Shimizu H, Ohtsuka M, Kato A, Yoshitomi $\mathrm{H}$ and Miyazaki M: Immunonutrition suppresses acute inflammatory responses through modulation of resolvin E1 in patients undergoing major hepatobiliary resection. Surgery 160(1): 228-236, 2016. PMID: 26965712. DOI: 10.1016/j.surg. 2016.01 .019

Received March 13, 2020

Revised April 6, 2020

Accepted April 8, 2020 